\title{
Correction of the single breath carbon monoxide transfer factor in exercise for variations in alveolar oxygen pressure
}

\author{
A H Kendrick, G Laszlo
}

\begin{abstract}
Background - Carbon monoxide transfer factor (TLCO) varies inversely with the partial pressure of alveolar oxygen $\left(\mathrm{PAO}_{2}\right)$. During exercise the $\mathrm{PAO}_{2}$ in the alveolar gas sample bag decreases so the TLCO increases more than would be expected from the effects of exercise alone. The effects of $\mathrm{PAO}_{2}$ on the estimation of TLCO during exercise have been investigated and studies have been performed to determine whether it is appropriate to standardise to a $\mathrm{PAO}_{2}$ of $16 \mathrm{kPa}$. Methods - TLCo was estimated at rest and at a single level of exercise in six normal subjects using test gas mixtures of $0.3 \%$ carbon monoxide, $14 \%$ helium, and oxygen in three different percentages $(17 \%, 21 \%$, and $27 \%)$, remainder nitrogen. In three of the subjects an incremental exercise test with estimates of oxygen consumption $\left(\dot{\mathrm{V}}_{2}\right)$ and cardiac frequency (fC) was also performed using a mixture containing $18 \%$ oxygen.

Results - TLCo decreased as levels of inspired oxygen increased. When standardised to a $\mathrm{PAO}_{2}$ of $16 \mathrm{kPa}$ TLCo became independent of the inspired oxygen concentration. The significance of the curvilinear relations of TLCO and transfer coefficient to $\dot{\mathrm{VO}}_{2}$ and $\mathrm{fC}$ improved.

Conclusion - The single breath breath holding TLCo should be standardised to a $\mathrm{PAO}_{2}$ of $16 \mathrm{kPa}$ when estimated during exercise.
\end{abstract}

\section{(Thorax 1994;49:82-84)}

The single breath breath holding transfer factor for carbon monoxide (TLCO) is inversely related to the alveolar partial pressure of oxygen $\left(\mathrm{PAO}_{2}\right)$, the reaction rate of carbon monoxide with oxyhaemoglobin being dependent on the concentration of oxygen..$^{1-3}$ During measurements on exercise the $\mathrm{PAO}_{2}$ decreases, as estimated from the expired gas sample, as the level of exercise increases from rest. The increases in TLCO seen on exercise will therefore not only reflect changes in the volume of blood in the alveolar capillaries and diffusing capacity of the alveolar-capillary membrane, ${ }^{4}$ but also decreases in $\mathrm{PAO}_{2}$.
Kanner and $\mathrm{Crapo}^{5}$ have recently investigated the effect of varying $\mathrm{PAO}_{2}$ on TLCO at rest and have derived an equation which standardises TLCO to a $\mathrm{PAO}_{2}$ of $16 \mathrm{kPa}$. This equation would permit standardisation of TLCO and overcome variations in the inspired level of oxygen and the effects of altitude.

The purpose of this study was to determine the effect of applying this equation to estimates of TLCo made during exercise.

\section{Methods}

SUBJECTS

Six women who were familiar with the exercise protocol participated in the study. Their mean (range) age was $23.5(20-27)$ years and body mass was $53.3(47 \cdot 1-54 \cdot 9) \mathrm{kg}$. All were nonsmokers and had no known cardiorespiratory disease. The level of customary occupational and leisure activity ${ }^{6}$ was recorded. All had an occupational activity of grade $2 \mathrm{~B}$ (sitting or standing, some walking; mostly indoors). Three had a leisure activity of grade 3 (regular activity), the others taking part in regular hard physical training (grade 4). All gave informed verbal consent and the study was approved by the local ethical committee.

\section{TRANSFER FACTOR}

Single breath TLCO was measured according to the method of Ogilvie et al, ${ }^{2}$ using the simultaneously estimated alveolar volume $(\mathrm{VA}) .^{\text {? }}$ TLCO was accepted if the volume inspired was greater than $80 \%$ of the vital capacity and the inspired and expired times were within those recommended. ${ }^{8}$ TLCo was calculated according to the American Thoracic Society (ATS) recommendations ${ }^{8}$ with the carbon monoxide transfer coefficient (KCO) calculated as TLCO/ VA,BTPS. All measurements were standardised to a haemoglobin concentration of $14.6 \mathrm{~g} / \mathrm{dl} .^{9}$ Measurements of carbon monoxide back tension were not made as this has been found to be unnecessary. ${ }^{10}$

\section{EXERCISE PROTOCOI}

The gas analysers and mass spectrometer were calibrated before any studies were performed. A four point calibration was performed on the 
mass spectrometer for nitrogen, oxygen, carbon dioxide, and argon, and a two point calibration on the carbon monoxide analyser. The volume of the spirometer was checked weekly with a seven litre calibration syringe (Hans Rudolf).

The exercise protocol used was that of Neville et $a l^{11}$ using six seconds of breath holding. Subjects were seated on the cycle ergometer (Lode, Holland) and resting measurements of oxygen uptake $\left(\dot{\mathrm{V}}_{2}\right)$ and cardiac frequency (fc) were made following a period of five minutes of quiet breathing. Estimates of resting TLCO and Kco were then obtained. The subjects then cycled for three minutes at a preset workload and a constant pedal rate of $60 \mathrm{rpm}$. At the end of the three minutes they continued to cycle and a single estimate of TLCO and Kco was obtained. For the incremental studies (study 2) the subject then rested for five minutes before the next level of exercise. An electrocardiogram was monitored continuously and a single lead ECG was recorded immediately before the breath hold test.

Mixed expired air was collected in a Tissot spirometer and analysed for oxygen and carbon dioxide using a mass spectrometer (VG Gas Analysis, UK). Inspired and expired oxygen concentrations and expired carbon dioxide concentrations from the TLCO estimates were also analysed using the mass spectrometer. Inspired and expired helium and carbon monoxide levels from the TLCo manoeuvre were analysed using a thermal conductivity and dispersive infrared gas analyser respectively. When analysing helium, carbon dioxide was absorbed, and the analyser compensated electrically for the different levels of inspired and expired oxygen. ${ }^{12}$

\section{Study 1}

To determine whether the equation of Kanner and Crapo was applicable to exercise, three exercise tests were performed with the above protocol. Measurements of TLCO, KCO, $\mathrm{Vo}_{2}$, and fC were made at rest and at a single level of exercise (100 watts). The test gas mixture was $0.3 \%$ carbon monoxide, $14 \%$ helium, and oxygen in three different percentages $(17 \%, 21 \%$, and $27 \%$ ), with nitrogen making up the remainder. Each exercise test was performed at the same time of day to avoid any possible diurnal variation, and subjects were asked not to eat and drink for one hour before exercise. Gas mixtures were allocated to each exercise test for a given subject in a single blind randomised manner.

Transfer factor and Kco were calculated as above with the expired helium concentration being corrected for the actual expired carbon dioxide. The equation of Kanner and Crapo: ${ }^{5}$

TLCO,STAN $=$ TLCO,OB $\times\left[1+0.0035\left(\mathrm{PAO}_{2}-120\right)\right]$ $\mathrm{mmol} / \mathrm{min} / \mathrm{kPa}$

was applied to the data, where TLCO,STAN and TLCO,OB are the standardised and observed values of TLCO respectively, and $\mathrm{PAO}_{2}$ is in $\mathrm{mm} \mathrm{Hg}$.
Study 2

To determine the effect of standardising for alveolar oxygen on the relations of TLCO and $\mathrm{Kco}$ to $\dot{\mathrm{VO}}_{2}$ and fc, the above exercise protocol was performed with increasing workloads of $25,50,75$, and 100 watts. The gas mixture used was $0.3 \%$ carbon monoxide, $14 \%$ helium, $18 \%$ oxygen, remainder nitrogen.

\section{DATA ANALYSIS}

The data were analysed with the Minitab package. ${ }^{13}$ To obtain the relation between the change in TLCO with increasing $\mathrm{PAO}_{2}$ the percentage difference in TLCO was determined. The relation was assessed by linear regression analysis, with its significance being established by analysis of variance as applied to regression. The relations of TLCO and $\mathrm{KCO}$ to $\mathrm{VO}_{2}$ and fC were determined by quadratic polynomial regression analysis ${ }^{10}$ before and after standardisation for $\mathrm{PAO}_{2}$, and the indices of TLCO and $\mathrm{KcO}$ at an fC of 150 beats/min and a $\dot{\mathrm{VO}}_{2}$ of $1.01 / \mathrm{min}$ were calculated.

\section{Results}

All six subjects completed the exercise tests for study 1 without difficulty. Three of the six subjects were exercised in study 2 . All estimates of TLCO were technically acceptable according to the ATS criteria, ${ }^{8}$ and each subject achieved an fC of greater than $80 \%$ predicted, indicating a maximum exercise test.

\section{Study 1}

The relation of the percentage difference between unstandardised and standardised TLCO $\left(\mathrm{TLCO}_{\text {diff }}\right)$ to alveolar partial pressure of oxygen at rest and on exercise is shown in the figure and given by the equation:

$$
\begin{gathered}
\mathrm{TLCO}_{\text {diff }}=42.4-2.65 \mathrm{PAO}_{2}(\mathrm{SE}=0 \cdot 21, \\
r=0.99, \mathrm{p}<0.001)
\end{gathered}
$$

from which the calculated $\mathrm{PAO}_{2}$ was $16.0 \mathrm{kPa}$ when $\mathrm{TLCO}_{\text {diff }}$ is zero.

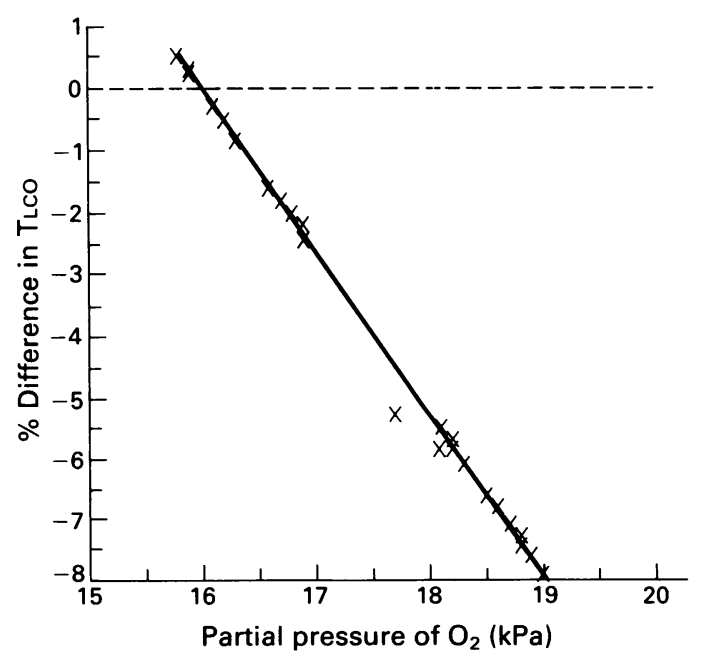

Relation of the percentage difference between unstandardised and standardised TLCO to the partial pressure of alveolar oxygen $(\mathrm{kPa})$. 
Study 2

The resting TLCo and $\mathrm{Kco}$ increased after standardisation (table 1). As exercise increased the $\mathrm{PAO}_{2}$ fell, and the TLCO and KCO at an fC of 150 beats $/ \mathrm{min}$ and at a $\dot{\mathrm{Vo}} \mathrm{O}_{2}$ of $1.0 \mathrm{l} / \mathrm{min}$ were lower after standardisation to $16 \mathrm{kPa}$ (table 1 ). The coefficient of variation for each subject for the VA was $3.65 \%, 2.0 \%$ and $2.2 \%$, and there was no significant reduction $(p<0.05)$ in VA as the exercise level increased. After standardisation the coefficients of determination for the relations of TLCO and $\mathrm{KCO}$ to $\dot{\mathrm{VO}}_{2}$ and fC improved in all subjects and all had a significantly improved correlation (table 2 ). The TLCO at 100 watts from study 1 using an inspired oxygen concentration of $17 \%$ in the three subjects was $11 \cdot 1,8 \cdot 81$, and $10 \cdot 12 \mathrm{mmol} /$ $\mathrm{min} / \mathrm{kPa}$ compared with $11.86,9.25$, and $10.37 \mathrm{mmol} / \mathrm{min} / \mathrm{kPa}$ in study 2 using an inspired oxygen concentration of $18 \%$.

\section{Discussion}

There has recently been interest in attempting to standardise the calculations of TLCo and recommendations have been made. ${ }^{14-16}$ One point of disagreement between the American and European recommendations is the level of inspired oxygen to be used during the test, and whether any standardisation for $\mathrm{PAO}_{2}$ should be arithmetic or simply by choosing the most appropriate inspired oxygen concentration. Furthermore, the European recommendations suggest standardisation to $14.5 \mathrm{kPa}$ rather than to $16 \mathrm{kPa}$ as proposed by the American Thoracic Society. ${ }^{8}$ To allow for differences in the inspired oxygen concentrations on TLCO at rest, Kanner and Crapo derived an empirical equation to standardise TLCO and KCO to a $\mathrm{PAO}_{2}$ of $16 \mathrm{kPa}$. The equation of Kanner and Crapo has not been applied to estimates of TLco during exercise.

It was the purpose of this study to investigate the effect of a decreasing $\mathrm{PAO}_{2}$ during

Table 1 Indices of TLCO $(\mathrm{mmol} / \mathrm{min} / \mathrm{kPa})$ and $\mathrm{KCO}(\mathrm{mmol} / \mathrm{min} / \mathrm{kPa} / \mathrm{l})$ at rest and during exercise in study 2

\begin{tabular}{|c|c|c|c|c|c|c|}
\hline \multirow[t]{2}{*}{ Index } & \multicolumn{2}{|c|}{ Subject 1} & \multicolumn{2}{|c|}{ Subject 2} & \multicolumn{2}{|c|}{ Subject 3} \\
\hline & $A$ & $B$ & $A$ & $B$ & $A$ & $B$ \\
\hline $\begin{array}{l}\text { TLCO } \\
\mathrm{KCO}_{\text {Rest }}\end{array}$ & $\begin{array}{c}10 \cdot 5 \\
2 \cdot 18\end{array}$ & $\begin{array}{c}10 \cdot 7 \\
2 \cdot 23\end{array}$ & $\begin{array}{l}8 \cdot 6 \\
2 \cdot 00\end{array}$ & $\begin{array}{l}8 \cdot 9 \\
2 \cdot 11\end{array}$ & $\begin{array}{l}7 \cdot 1 \\
1.94\end{array}$ & $\begin{array}{l}7 \cdot 3 \\
2 \cdot 02\end{array}$ \\
\hline $\begin{array}{l}\operatorname{TLCO}_{1 \cdot 0} \\
\mathrm{KCO}_{1 \cdot 0}\end{array}$ & $\begin{array}{c}12 \cdot 5 \\
2 \cdot 58\end{array}$ & $\begin{array}{c}11 \cdot 7 \\
2 \cdot 43\end{array}$ & $\begin{array}{c}10 \cdot 2 \\
2 \cdot 44\end{array}$ & $\begin{array}{c}10 \cdot 1 \\
2 \cdot 41\end{array}$ & $\begin{array}{l}9 \cdot 1 \\
2 \cdot 55\end{array}$ & $\begin{array}{l}8 \cdot 8 \\
2 \cdot 47\end{array}$ \\
\hline $\begin{array}{l}\mathrm{TLCO}_{150} \\
\mathrm{KCO}_{150}\end{array}$ & $\begin{array}{c}12 \cdot 6 \\
2 \cdot 61\end{array}$ & $\begin{array}{c}11.8 \\
2.48\end{array}$ & $\begin{array}{c}10 \cdot 8 \\
2 \cdot 60\end{array}$ & $\begin{array}{c}10 \cdot 4 \\
2.53\end{array}$ & $\begin{array}{l}9.4 \\
2.59\end{array}$ & $\begin{array}{l}9 \cdot 1 \\
2 \cdot 48\end{array}$ \\
\hline
\end{tabular}

TLCO = carbon monoxide transfer factor; $\mathrm{KCO}=$ carbon monoxide transfer coefficient. $\mathrm{TLCO}_{1 \cdot 0}$ and $\mathrm{KCO}_{1.0}$ are estimates at $1.0 \mathrm{l} / \mathrm{min}$ oxygen uptake, while $\mathrm{TLCO}_{150}$ and $\mathrm{KCO}_{150}$ are estimates at a cardiac frequency of 150 beats/min. For each subject column $A$ is unstandardised and column $B$ is standardised for $\mathrm{PAO}_{2}$.

Table 2 Coefficients of determination for the relationships of TLCO and $\mathrm{KcO}$ to $\mathrm{VO}$ and $f C$

\begin{tabular}{|c|c|c|c|c|c|c|c|c|}
\hline \multirow[t]{2}{*}{ Subject } & \multicolumn{2}{|c|}{ TLCO to $\mathrm{VO}_{2}$} & \multicolumn{2}{|c|}{$\mathrm{Kco}$ to $\mathrm{VO}_{2}$} & \multicolumn{2}{|c|}{ TLCO to fC } & \multicolumn{2}{|c|}{$K c o$ to $f C$} \\
\hline & $A$ & $B$ & $A$ & $B$ & $A$ & $B$ & $A$ & $B$ \\
\hline $\begin{array}{l}2 \\
3\end{array}$ & $\begin{array}{l}0.886 \\
0.966^{*} \\
0.991^{* *}\end{array}$ & $\begin{array}{l}0.912^{*} \\
0.990^{* *} \\
0.991^{* *}\end{array}$ & $\begin{array}{l}0.829 \\
0.967^{*} \\
0.994^{* *}\end{array}$ & $\begin{array}{l}0.927^{*} \\
0.979^{*} \\
0.996^{* *}\end{array}$ & $\begin{array}{l}0.953^{*} \\
0.987^{* *} \\
0.979^{*}\end{array}$ & $\begin{array}{l}0.954^{*} \\
0.997^{* *} \\
0.982^{* *}\end{array}$ & $\begin{array}{l}0.840 \\
0.916^{*} \\
0.986^{* *}\end{array}$ & $\begin{array}{l}0.930^{*} \\
0.932^{*} \\
0.990^{* *}\end{array}$ \\
\hline
\end{tabular}

TLCO=carbon monoxide transfer factor; $\dot{\mathrm{V}}_{2}=$ oxygen consumption; KCO=carbon monoxide transfer coefficient; $f C=$ cardiac frequency. For each subject column $A$ is unstandardised and column $\mathrm{B}$ is standardised for $\mathrm{PAO}_{2}$.

${ }^{*} \mathrm{p}<0.05 ;{ }^{* *} \mathrm{p}<0.01$. breath holding as the level of exercise increased. There are two reasons why applying this correction might increase the accuracy of the test as an indicator of normality. Firstly, the inspired oxygen concentration will determine the $\mathrm{PAO}_{2}$ which is related, though not tied to, the partial pressure of capillary oxygen $\left(\mathrm{PcO}_{2}\right) \cdot{ }^{3}$ As the level of exercise increases so the $\mathrm{PAO}_{2}$ obtained during breath holding will decrease, resulting in a decrease in $\mathrm{PcO}_{2}$ and hence an increase in TLCo. Secondly, $\dot{\mathrm{VO}}_{2}$, and therefore $\mathrm{Po}_{2}$, during breath holding depends on the flow of reduced haemoglobin into the lungs. For any given blood flow the rate of decline in $\mathrm{PO}_{2}$ will vary inversely with the alveolar volume. Our results confirm these theoretical predictions. We suggest that TLCO should be standardised for $\mathrm{PAO}_{2}$ if changes in TLCO and Kco are to reflect increases in the vascularity of the lungs and in the area of the diffusion pathway.

In conclusion, an empirical correction of TLCO to allow for $\mathrm{PAO}_{2}$ can be used during exercise. Use of this correction reduces the error in the prediction of change of TLCO with exercise and appears to yield valid results regardless of the level of exercise or of oxygen uptake. It is recommended for use in the calculation of TLCO in exercise.

We thank the subjects for their assistance in this study, which was supported by grants from the Special Trustees, United Bristol Hospitals and the South Western Regional Health Authority.

1 Forster RE, Roughton FJW, Cander L, Briscoe WA, Kreuzer A. Apparent pulmonary diffusing capacity for $\mathrm{CO}$ at varying alveolar $\mathrm{O}_{2}$ tensions. $\mathcal{f} \mathrm{Appl}$ Physiol 1957;11:277-89.

2 Ogilvie CM, Forster RE, Blakemore WS, Morton A. A standardized breath-holding technique for the clinical measurement of the diffusing capacity of the lung for carbon monoxide. $\mathcal{F}$ Clin Invest 1957;36:1-17.

3 Roughton FJW, Forster RE. Relative importance of diffusion and chemical reaction rates in determining rate of exchange of gases in the human lung, with special reference to true diffusing capacity of the pulmonary membrane and volume of blood in the lung capillaries. $\mathcal{f} \mathrm{Appl}$ Physiol 1957;11:290-302.

4 Brewin M, Higgs CMB, Hudson T, Kendrick AH, Laszlo $G$, Tanser A. Effect of exercise on the diffusing capacity of the alveolar capillary membrane $\left(D_{m}\right)$ and the volume of blood in the alveolar capillaries $\left(\mathrm{Q}_{\mathrm{c}}\right)^{\mathrm{m}}$. $\mathcal{F}$ Physiol (Lond) 1988;406:98P.

5 Kanner RE, Crapo RO. The relationship between alveolar oxygen tension and the single-breath carbon monoxide diffuing

6 Saltin B, Grimby G. Physiological analysis of middle-aged and old former athletes. Circulation 1968;38:1104-15.

7 and old former athletes. Circulation 1968;38:1104-15. and lung volume change on alveolar capillary permeabiand lung volume change on alveolar capillary permeability and diffusing

8 American Thoracic Society. Single-breath carbon monoxide diffusing capacity (transfer factor): recommendations for a standard technique. Am Rev Respir Dis 1987;136:1299-307.

9 Cotes JE, Dabbs JM, Elwood PC, Hall AM, McDonald A, Saunders MJ. Iron-deficiency anaemia: its effects on transfer factor for the lung (diffusing capacity) and ventilation and cardiac frequency during submaximal exercise. Clin Sci 1972;42:325-35.

10 Kendrick AH, Cullen J, Green H, Papouchado M, Laszlo G. Measurement of single-breath carbon monoxide transer factor (diffusing capacity) during progr transfer factor (diffusing capacity) during progressive

11 Neville E, Kendrick AH, Gibson GJ A standardized method of estimating $\mathrm{KCO}$ on exercise. Thorax method of 798 .

12 Morgan PK. Physical gas analysers. In: Laszlo G, Sudlow MF, eds. Measurement in clinical respiratory physiology. MF, eds. Measurement in clinical respira

13 Ryan BF, Joiner BL, Ryan TA. Minitab. 2nd ed. Boston: Ryan BF, Joiner BL, Ryar
Duxbury Press, 1985.

14 Ferris BG. Epidemiology standardization project. Am Rev Respir Dis 1978;118(Suppl):62-72.

15 Quanjer PhH. Standardized lung function testing. Eur Respir $\mathcal{F}$ 1993;6:Suppl 16.

16 Morris AH, Crapo RO. Standardization of computation of single-breath transfer factor. Bull Eur Physiopathol Respir 1985;21:183-9. 